\title{
Pregnancy rate in lactating Bos indicus cows subjected to fixed-time artificial insemination and treated with different follicular growth inducers
}

\section{Ériklis Nogueira ${ }^{1}$, Dayanna Schiavi do Nascimento Batista ${ }^{1}$, Luiz Carlos Cesar da Costa Filho², Alexandre Menezes Dias ${ }^{2}$, Juliana Corrêa Borges Silva ${ }^{1}$, Luís Carlos Vinhas Ítavo ${ }^{3}$}

\author{
1 Embrapa Pantanal, Corumbá, MS, Brasil. \\ ${ }^{2}$ Universidade Federal de Mato Grosso do Sul, Campo Grande, MS, Brasil. \\ ${ }^{3}$ Universidade Católica Dom Bosco, Campo Grande, MS, Brasil.
}

\begin{abstract}
The objective of this experiment was to evaluate the effects of replacing eCG with FSH or FSH/LH on the diameter of ovulatory follicles (DOF) and the pregnancy rates (PR) of lactating Bos indicus cows subjected to a synchronization of ovulation protocol and fixed-time artificial insemination (FTAI) based on progesterone, estradiol benzoate (EB), PGF2 $\alpha$, and estradiol cypionate $(\mathrm{EC})$. On day 0, primiparous and multiparous Nellore cows $(\mathrm{n}=329)$ at 68 days postpartum were body condition scored (BCS) and received a P4 implant (PRIMER $1.0 \mathrm{~g}$ P4) plus $2 \mathrm{mg}$ EB intramuscularly (IM). At day 8, the implant was removed, and $250 \mu \mathrm{g}$ cloprostenol were injected IM along with $0.5 \mathrm{mg}$ EC. At the time of implant removal, the animals were divided into one of four treatments: cows received (G1) $1 \mathrm{~mL}$ of saline solution IM (Control; $\mathrm{n}=80$ ); (G2) $300 \mathrm{IU}$ eCG IM (ECG300; n = 84); (G3) 15 mg FSH IM (Folltropin; $\mathrm{n}=82$ ); and (G4) 30 IU FSH/LH IM (Pluset; $\mathrm{n}=83$ ); all cows were subjected to FTAI 48-54 h after implant removal (day 10). Transrectal ultrasonography was performed to measure the DOF to FTAI and to estimate the pregnancy rate on day 35. A statistical analysis examined the effects of the treatment, technician, semen, BCS, calf age and parity on PR to FTAI. There was no significant difference in PR and DOF among the treatment groups (G1, 41.3\%, $13.1 \mathrm{~mm}$; G2, 46.4\%, $14.5 \mathrm{~mm}$; G3, 46.3\%, $14.2 \mathrm{~mm}$; and G4, 48.2\%, $14.3 \mathrm{~mm}$ ), but PR was higher in multiparous than in primiparous cows. Commercial FSH solutions (Pluset or Folltropin) do not promote increases in PR or DOF of lactating Nellore cows and are equal to eCG in promoting growth in preovulatory follicles and elevating the PR in Nellore cows with a moderate BCS subjected to a progesterone-based FTAI protocol with EC.
\end{abstract}

Key Words: FSH, multiparous, Nellore, primiparous

\section{Introduction}

Nellore is the predominant Zebu (B. indicus) cattle breed in Brazil and represents $80 \%$ of all beef cattle (above 100 million Nellore animals), and its use continues to spread in Brazil and other tropical and subtropical countries (Sartori and Barros, 2011). These tropical regions are characterized by high precipitation rates and high temperatures, which provide favorable conditions for forage growth and lowcost beef production.

Although artificial insemination (AI) is an important tool for improving the genetic gain and the production efficiency of large herds of beef cattle - a common situation in Brazil -, the ability to detect estrus in cows and inseminate them is limited. Thus, the related infrastructure and staff have limited performance, which increases the

Received May 14, 2013 and accepted February 21, 2014.

Corresponding author: eriklis.nogueira@embrapa.br

http://dx.doi.org/10.1590/S1516-35982014000700003

Copyright @ 2014 Sociedade Brasileira de Zootecnia. This is an Open Access article distributed under the terms of the Creative Commons Attribution Non-Commercial License, which permits unrestricted non-commercial use, distribution, and reproduction in any medium, provided the original work is properly cited. cost-benefit relationship in herds where a low number of cows can be managed efficiently.

Estrous synchronization protocols that allow for the insemination of many females over a period of predetermined time (fixed-time artificial insemination; FTAI) have been developed in Brazil. The hormones primarily used are the progestagens, the prostaglandins and its analogues, and estradiol. Additionally, the use of equine chorionic gonadotropin (eCG) as an inducer of follicular growth has improved the efficacy of FTAI protocols and increased the ovulatory responses and pregnancy rates in beef cattle in situations involving low body condition scores (BCS), recent postpartum and anestrus (Peres et al., 2009; Sá Filho, et al., 2010). Equine chorionic gonadotropin is a long half-life molecule produced by the endometrial cup cells of mares (Murphy and Martinuk, 1991), and it has a stimulatory effect, like the FSH and LH hormones, leading to increased follicular growth and ovulation (Baruselli et al., 2003; Sales et al., 2011).

However, there are other gonadotropins such as FSH in different commercial applications (among them, FSH $\left[\right.$ Folltropin $\left.^{\circledR}\right]$ and combinations of FSH and LH [Pluset $\left.{ }^{\circledR}\right]$ stand out) that could be potentially used to increase 
follicular growth, but with controversial results (Santos et al., 2007a,b; Sá Filho et al., 2009; Martins et al., 2010; Sales et al., 2011). The half-life of FSH is reportedly shorter $(<2 \mathrm{~h})$ than that of eCG (Fry et al., 1987), and the underlying cellular mechanism whereby FSH induces follicular development is mediated through an increased number of FSH receptors in granulosa cells.

The objective of this experiment was to evaluate the effects of replacing eCG by FSH or FSH/LH on the diameter of ovulatory follicles and the pregnancy rates of lactating Nellore cows subjected to a synchronization of ovulation protocol based on progesterone, EB, PGF2 $\alpha$, and EC. The hypothesis was that FSH or FSH/LH could replace the eCG treatment in the FTAI protocols of Nellore cows.

\section{Material and Methods}

The study was conducted from November 2008 to January 2009 on commercial beef cattle properties in Mato Grosso do Sul State, Brazil (temperature range $21-32{ }^{\circ} \mathrm{C}$ ). Lactating Nellore cows $(n=329$; at an average of $68 \mathrm{~d}$ postpartum; BCS 2.61 on a scale of 1-5, at day 0) were kept on two farms on Brachiaria decumbens pastures with ad libitum access to water and mineral supplements and were evaluated by transrectal ultrasonography to access their ovarian status. They were treated with the following basic synchronization of ovulation protocol: insertion of $1.0 \mathrm{~g}$ progesterone (PRIMER; Tecnopec, São Paulo, Brazil) intravaginally as well as $2.0 \mathrm{mg}$ Estradiol Benzoate (EB) $(2.0 \mathrm{~mL}$ of Estrogin; Farmavet, São Paulo, Brazil) intramuscularly (IM) on day 0 . On day 8 , all cows had PRIMER inserts removed and received $0.5 \mathrm{mg}$ Estradiol Cypionate (EC) $(0.25 \mathrm{~mL}$ of E.C.P.; Pfizer Animal Health, Brazil) IM and $12.5 \mathrm{mg}$ PGF2 $\alpha$ (2.5 mL of Lutalyse; Pfizer Animal Health, Brazil) IM. Immediately after the PRIMER withdrawal, cows were randomly assigned to receive one of the following treatments: (G1) $2 \mathrm{~mL}$ of saline solution IM (Control; $\mathrm{n}=80)$; (G2) 300 IU eCG IM ( $\mathrm{n}=84)$; (G3) 15 mg FSH (Folltropin-V; Bioniche Animal Health, Belleville, ON, Canada; FSH:LH proportion >80.0\%) IM ( $=82)$; (G4) 30 IU FSH/LH $(0.5 \mathrm{~mL}$ of Pluset; Hertape - Calier, São Paulo, Brazil; FSH/LH proportion approximately $50.0 \%)$ IM $(n=83)$. On day $10(48-54 \mathrm{~h}$ after CIDR withdrawal), all cows received FTAI. The cows were inseminated by one of two experienced technicians with frozen-thawed semen randomly chosen from one of the three donor sires evaluated previously.

The diameter of the largest follicle was determined on the day of FTAI by averaging the length and width measurements from the ovarian transrectal ultrasonography with a Falcon 100 Scanner with a linear probe (8.0 MHZ). Pregnancy was diagnosed $35 \mathrm{~d}$ after FTAI using transrectal ultrasonography. The pregnancy rate was calculated by dividing the number of pregnant cows by the number of treated cows.

The semen morphology and motility were evaluated (Barth and Oko, 1989) and approved with the minimum parameters (motility $<30 \%$, total defects $>30 \%$, vigor $\leq 3$ ) according to the Colégio Brasileiro de Reprodução Animal (CBRA) manual (Henry and Neves, 1998) and sires were distributed equally among the experimental groups in the experiment.

Binomial variable pregnancy rates were analyzed using PROC LOGISTIC in the SAS program (Statistical Analysis System, version 9.2). Explanatory variables such as treatment, BCS at day 0 , parity, days postpartum, and farm were used in the model as classes. For the pregnancy data, the original models also included the effects of sire and the AI technician. For all logistic regression models, all two-way interactions were tested. When a significant effect of a covariate $x$ on a dependent variable $y$ was detected, logistic regression curves were created using the coefficients provided by the software and the formula $y=$ $\operatorname{EXP}(a \times x+b) /[1+\operatorname{EXP}(a \times x+b)]$.

The follicular diameter data were subjected to analysis of variance, and differences between the means were tested using Tukey's test by the PROC GLM procedure of the SAS program $(\mathrm{P}<0.05)$. The results are presented as the mean \pm standard deviation. Differences with $\mathrm{P}<0.05$ were considered significant.

\section{Results and Discussion}

The diameter of the preovulatory follicle assessed at the time of FTAI did not differ between treatments (G1, $12.4 \pm 2.97 \mathrm{~mm}$; G2, $14.3 \pm 2.90 \mathrm{~mm}$; G3, $13.8 \pm 2.64 \mathrm{~mm}$; $\mathrm{G} 4,13.5 \mathrm{~mm} \pm 3.44, \mathrm{P}>0.05$ ), but was affected by parity (multiparous, $14.38 \pm 2.70$; primiparous, $12.19 \pm 3.18 ; \mathrm{P}=0.003$ ). No interaction between treatments and parity was found $(\mathrm{P}=0.92)$. The follicle diameter affected the probability of pregnancy positively, including BCS at the time of the implant removal $(\mathrm{P}<0.01)$ (Figures 1 and 2$)$.

Using Folltropin (80\% FSH/20 LH\%) and Pluset $(50 \% \mathrm{FSH} / 50 \% \mathrm{LH})$ and replacing eCG in FTAI protocols in postpartum, Nellore cows showed similar results for preovulatory follicle diameter and pregnancy rate $(\mathrm{P}>0.05)$, although this method showed no advantages in G1 (Table 1).

Baruselli et al. (2003) and Cutaia et al. (2003) reported that 0 or $400 \mathrm{IU}$ eCG were administered to cows undergoing progesterone-device removal in a synchronization protocol 


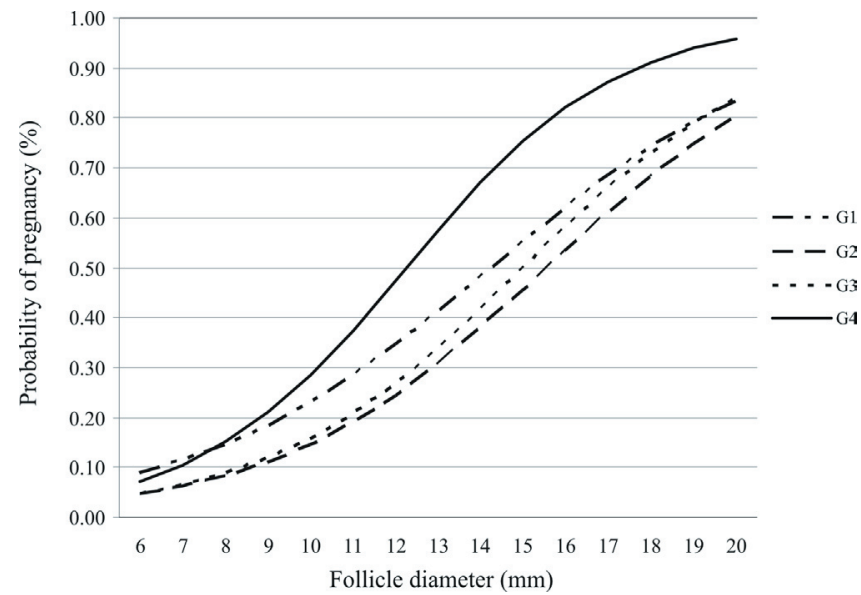

Figure 1 - Effect of follicle diameter at day 10 on the probability of pregnancy in postpartum Nellore cows subjected to progesterone-based FTAI protocol $(\mathrm{P}<0.01)$.

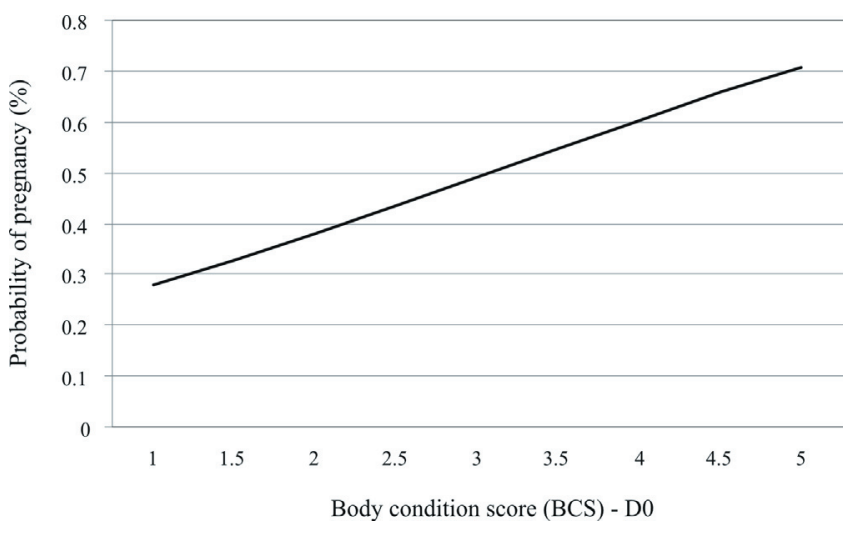

Figure 2 - Effect of body condition score at day 0 on the probability of pregnancy in postpartum Nellore cows subjected to a progesterone-based FTAI protocol $(\mathrm{P}<0.05)$.

Table 1 - Effects of treatments at implant removal on follicle diameter at FTAI (FD) and pregnancy rate (PR) in Nellore cows subjected to progesterone-based fixed-time insemination protocol

\begin{tabular}{|c|c|c|c|c|c|}
\hline & $\operatorname{BCS}(1-5)$ & $\mathrm{FD} \pm \mathrm{SD}(\mathrm{mm})$ & P-value & PR \% (pregnant, $\mathrm{n}$ ) & P-value \\
\hline \multicolumn{6}{|l|}{ Treatment } \\
\hline Control & 2.57 & $12.40 \pm 2.97$ & \multirow{3}{*}{0.33} & $41.2(33 / 80)$ & \multirow{3}{*}{0.155} \\
\hline eCG & 2.58 & $14.31 \pm 2.90$ & & $46.4(39 / 84)$ & \\
\hline Pluset & 2.71 & $13.54 \pm 3.44$ & & $48.2(40 / 83)$ & \\
\hline \multicolumn{6}{|l|}{ Farm } \\
\hline Farm 1 & 2.67 & $13.82 \pm 3.01$ & 0.37 & $53.9(69 / 128)$ & 0.001 \\
\hline \multicolumn{6}{|l|}{ Parity } \\
\hline Primiparous & 2.59 & $12.19 \pm 3.18$ & \multirow{2}{*}{0.003} & $38.8(45 / 116)$ & \multirow{2}{*}{0.004} \\
\hline Multiparous & 2.66 & $14.38 \pm 2.70$ & & $49.3(105 / 213)$ & \\
\hline \multicolumn{6}{|l|}{ Bull } \\
\hline 1 & 2.70 & & & $57.8(63 / 109) \mathrm{a}$ & \multirow[b]{2}{*}{0.05} \\
\hline 2 & 2.69 & & & $31.8(35 / 110) b$ & \\
\hline
\end{tabular}

BCS - body condition score; SD - standard deviation.

$\mathrm{a} \neq \mathrm{b}(\mathrm{P}<0.05)$.

for FTAI. The equine chorionic gonadotropin treatment increased pregnancy rates in Bradford (26.7 vs. 34.6\%), Nellore (38.9 vs. $45.7 \%$ ) and crossbred Nellore cows (46.8 vs. 59.1\%). Bergamaschi et al. (2005), treating cows with a protocol similar to that of Baruselli et al. (2003), also showed that despite the similar size of the preovulatory follicle, both the size of CL and the plasma concentrations of progesterone after estrus increased for cows that received $400 \mathrm{IU} \times 0 \mathrm{IU}$ eCG. Nevertheless, it is important to mention that the eCG effectiveness varies with the body condition score (BCS), the number of days postpartum and the association with other management strategies, such as temporary weaning (Binelli et al., 2009).

As with eCG, the use of Pluset or Folltropin was not able to increase pregnancy rate and size of the preovulatory follicle in postpartum Bos indicus cows with a moderate body condition score (BCS average of 2.61 on a scale of 1-5). These results agree with authors who used Folltropin (Santos et al., 2007 a,b; Martins et al., 2010), but is in contrast to others who used only Folltropin (Sales et al., 2011; Lima et al., 2010) or Folltropin and Pluset (Sá Filho et al., 2009). In our study the BCS at implant had a positive effect on the probability of pregnancy $(\mathrm{P}<0.05)$ (Figure 2).

In cattle, eCG treatment promotes follicle growth in single dosages, which is likely due to the long metabolic half-life ( $>50$ h) (Menzer and Schams, 1979). In contrast, Folltropin-V and Pluset are reported to contain $87 \%$ and $50 \%$ of FSH (Mapletof et al., 1993), respectively, and its metabolism appears to be relatively fast. After intramuscular administration, the half-life and the disappearance of the porcine FSH were estimated at $5 \mathrm{~h}$ and $10-12 \mathrm{~h}$, respectively (Demonstier et al., 1988). Although follicles are more 
dependent on LH after the deviation process (Ginther et al., 1996), some investigators have indicated the presence of active FSH receptors, even dominant follicles $(>10 \mathrm{~mm})$ that can be stimulated by a single injection of FSH.

The amount of LH in the preparation of FSH may influence the dosage of FSH required in superovulation, since the granulosa cells from the follicles are predominantly more LH-dependent, not only using FSH maturation until ovulation (Adams et al., 1992). Salles et al. (2011), who only used Folltropin, suggest that a less purified FSH (which has a greater amount of LH, like Pluset) may also produce results comparable to those found in the eCGFTAI protocols in beef cattle, which was not confirmed in our study. The lower effect of treatment with FSH found in some studies that used Folltropin or Pluset may be due to the dosage used in these studies. Sales et al. (2011) and Sá Filho et al. (2009) used $10 \mathrm{mg}$ of Folltropin and $25 \mathrm{IU}$ of Pluset. In our study we used $15 \mathrm{mg}$ Folltropin and 30 IU Pluset.

Some studies have demonstrated the effect of eCG on the improvement of the pregnancy rates of postpartum cows, with a more pronounced effect on those with a lower BCS or those that were anestrous (Baruselli et al., 2004; Sá Filho et al., 2010). When animals with good BCS, or with estrous cyclicity were undergoing the eCG treatment, it was shown that eCG did not promote an increase in preovulatory follicles or in pregnancy rates (Salles et al., 2011; Pinheiro et al., 2009).

Another finding that explains our results regards the estrous cyclic patterns of cows in our study, in which $59.8 \%$ (197/329) of animals showed a CL or follicles $>10$ $\mathrm{mm}$, whereas in other studies (Salles et al., 2011; Sá Filho et al., 2009) the animals used were in anestrus. In these animals Sá Filho et al. (2010) and Baruselli et al. (2003) showed that eCG was more effective in inducing pregnancy in FTAI protocols when 400 IU were used. In our study we used $300 \mathrm{IU}$ of eCG.

The diameter of the preovulatory follicle was affected by parity order (multiparous, $14.38 \pm 2.70$, primiparous, $12.19 \pm 3.18, \mathrm{P}<0.05$ ) as well as by pregnancy rate (multiparous $49.3 \%$; primiparous, $38.8 \%$ ); however, no interaction was found between parity and treatment $(\mathrm{P}>0.05)$. Pinheiro et al. (2009) demonstrated an increase in the pregnancy rate of multiparous cows compared with primiparous cows when they were subjected to FTAI protocols based on progesterone, as was observed in this study. The increased demand for nutrients in primiparous cows associated with the inhibitory effect of suction can promote a lower frequency of $\mathrm{LH}$ pulses in these animals, leading to a lower pregnancy rate.

Pregnancy rates were influenced by the semen used (bull 1 - 57.8\%; bull $2-31.8 \%$, bull $3-45.5 \%(\mathrm{P}<0.05)$ ) and the farm $(\mathrm{P}<0.01)$ (farm 1 - 53.9\%; farm 2 - 40.3\%). The pregnancy rate was not affected by the inseminator or the calf age $(\mathrm{P}>0.05)$. Some authors have shown that the semen used in FTAI has a large impact on pregnancy rate (Sá Filho et al., 2009; Andersson et al., 2004; Correa et al., 1997). As we observed in this study, there was a difference in pregnancy rate depending on the semen that was used, despite the fact that all met the minimum standards of motility and vigor, as suggested by the CBRA (Henry and Neves, 1998). Future research could identify variables that predict semen fertility in inseminated cows.

\section{Conclusions}

Commercial solutions of follicle-stimulating hormones (Pluset or Folltropin) provide no increase in pregnancy rates or in the diameter of the preovulatory follicle of postpartum cows and are equal to equine chorionic gonadotropin in promoting growth in the preovulatory follicle and increasing pregnancy rates in Nellore cows of moderate body-condition score subjected to a fixed-time artificial insemination protocol using estradiol cypionate.

\section{References}

Adams, G. P.; Matteri, R. L.; Kastelic, J. P.; Ko, J. C. H. and Ginther, O. J. 1992. Association between surges of follicle-stimulating hormone and the emergence of follicular waves in heifers. Journal of Reproduction and Fertility 94:177-188.

Andersson, M.; Taponen, J.; Koskinen, E. and Dahlbom, M. 2004. Effect of insemination with doses of 2 or 15 million frozen-thawed spermatozoa and semen deposition site on pregnancy rate in dairy cows. Theriogenology 61:1583-1588.

Barth, A. D. and Oko, R. J. 1989. Abnormal morphology of bovine spermatozoa. Iowa State University Press, Ames.

Baruselli, P. S.; Marques, M. O.; Nasser L. F.; Reis, E. L. and Bó, G. A. 2003. Effect of eCG on pregnancy rates of lactating zebu beef cows treated with cidr-b devices for timed artificial insemination. Theriogenology 59:214.

Baruselli, P. S.; Reis, E. L.; Marques, M. O.; Nasser L. F. and Bó, G. A. 2004. The use of hormonal treatments to improve reproductive performance of anestrous beef cattle in tropical climates. Animal Reproduction Science 82:479-486.

Bergamaschi, M. A. C. M.; Vicente, W. R. R.; Barbosa, R. T.; Machado, R.; Baruselli, P. S.; Alencar, M. and Binelli, M. 2005. Estratégias hormonales para optimizar la función luteínica de vacas nelore posterior a la sincronización del estro. p.154. (abstract). In: Anales del $12^{\circ}$ Congresso Latinoamericano de Buiatria; $7^{\mathrm{a}}$ Jornadas Chilenas de Buiatria, Valdivia, Chile. Sociedad Chilena de Buiatria, Osorno, Chile.

Binelli, M.; Machado, R.; Bergamaschi, M. A. C. M. and Bertran, C. M. 2009. Manipulation of ovarian and uterine function to increase conception rates in cattle. Animal Reproduction 6:125-134.

Correa, J. R.; Pace, M. M. and Zavos, P. M. 1997. Relationships among frozen-thawed sperm characteristics assessed via the routine semen analysis, sperm functional tests and fertility of bulls in an artificial insemination program. Theriogenology 48:721-731.

Cutaia, L.; Tríbulo, R.; Moreno, D. and Bó, G. A. 2003. Pregnancy rates in lactating beef cows treated with progesterone releasing 
devices, estradiol benzoate and equine chorionic gonadotropin (eCG). Theriogenology 59:216.

Demostier, M. M.; Beckers, J. F.; van der Zwalmen, P.; Closset, J.; Gillard, J. and Ectors, F. R. 1988. Determination of porcine plasma folltropin levels during superovulation treatment in cows. Theriogenology 30:379-386.

Fry, R. C.; Cahill, L. P.; Cummins, J. T.; Bindon, B. M.; Piper, L. R. and Clarke, I. J. 1987. The half-life of follicle-stimulating hormone in ovary-intact and ovariectomized booroola and control merino ewes. Journal of Reproduction and Fertility 81:611-615.

Ginther, O. J.; Wiltbank, M. C. and Fricke, P. M. 1996. Selection of the dominant follicle in cattle. Biology of Reproduction 55:1187-1194.

Lima, L. A.; Pinheiro, V. G.; Cury, J. R. and Barros, C. M. 2010. Addition of $\mathrm{FSH}$, in contrast to eCG, does not increase pregnancy rates in anestrous Nellore (Bos indicus) cows treated with fixedtime AI protocol. Reproduction Fertility and Development 22:170.

Henry, M. and Neves, J. P. 1998. Manual para exame andrológico e avaliação de sêmen animal. 2.ed. Colégio Brasileiro de Reprodução Animal, Belo Horizonte.

Martins, C. M.; Valentim, R.; Bombonatto, D. S.; Santos, I. C. C. and Baruselli, P. S. 2010. Folltropin was as efficacious as eCG in treating cows for fixed-time. Acta Scientiae Veterinariae 38:731.

Mapletoft, R. J. and Pierson, R. A. 1993. Factors affecting superovulation in the cow: practical considerations. Embryo Transfer News and Articles 11:15-24.

Menzer, C. and Schams, D. 1979. Radioimmunoassay for PMSG and its application to in vivo studies. Journal of Reproduction and Fertility 55:339-345.

Murphy, B. D.; Martinuk, S. D. 1991. Equine chorionic gonadotropin. Endocrine Rewiews 12:27-44.

Peres, R. F.; Claro Jr. I.; Sá Filho, O. G.; Nogueira, G. P. and Vasconcelos, J. L. M. 2009. Strategies to improve fertility in
Bos indicus postpubertal heifers and nonlactating cows submitted to fixed-time artificial insemination. Theriogenology 72:681-689.

Pinheiro, V. G.; Souza, A. F.; Pegorer, M. F.; Satrapa, R. A.; Ereno, R. L.; Trinca, L. A. and Barros, C. M. 2009. Effects of temporary calf removal and eCG on pregnancy rates to timed-insemination in progesterone-treated postpartum Nellore cows. Theriogenology 71:519-524.

Sales, J. N. S.; Crepaldi, G. A.; Girotto, R. W.; Souza, A. H. and Baruselli, P. S. 2011. Fixed-time AI protocols replacing eCG with a single dose of FSH were less effective in stimulating follicular growth, ovulation, and fertility in suckled anestrus Nelore beef cows. Animal Reproduction Science 124:12-18.

Sá Filho, O. G.; Meneghetti, M.; Peres, R. F. G.; Lamb, G. C. and Vasconcelos, J. L. M. 2009. Fixed-time artificial insemination with estradiol and progesterone for Bos indicus cows II: Strategies and factors affecting fertility. Theriogenology 72:210-218.

Sá Filho, M. F.; Ayres, H.; Ferreira, R. M.; Marques, M. O.; Reis, E. L.; Silva, R. C.; Rodrigues, C. A.; Madureira, E. H.; Bó, G. A. and Baruselli, P. S. 2010. Equine chorionic gonadotropin and gonadotropin-releasing hormone enhance fertility in a norgestomet-based, timed artificial insemination protocol in suckled Nelore (Bos indicus) cows. Theriogenology 73:651-658.

Santos, I. C. C.; Martins, C. M.; Valentim, R. and Baruselli, P. S. 2007a. Pregnancy rate in FTAI anestrous Bos indicus cows treated with a single dose of FSHp (Folltropin). Acta Scientiae Veterinariae $35: 1151$

Santos, I. C. C.; Martins, C. M.; Baruselli, P. S.; Valentim, R. and D'Occhio, M. 2007b. Study of follicular dinamics in anestrous Nelore cows (Bos indicus) synchronized with FTAI protocol using folltropin ${ }^{\circledR}$ (FSHp) as folicular growth inductor. Acta Scientiae Veterinariae 35:1152.

Sartori, R. and Barros, C. M. 2011. Reproductive cycles in Bos indicus cattle. Animal Reproduction Science 124:244-250. 